\title{
Generation Revenue Assessment in Malaysia Electricity Supply Industry
}

\author{
Zuraidah Ngadiron $^{1, a}$, N.H Radzi ${ }^{1, b}$, Zaris Yassin ${ }^{1}$ \\ ${ }^{1}$ Faculty of Electrical and Electronic Engineering, Universiti Tun Hussein Onn Malaysia, Parit Raja, \\ Batu Pahat, 86400 Johor, Malaysia. \\ azuraidahn@gmail.com.my, 'burhanis@uthm.edu.my
}

Key Words: Malaysia Electricity Supply Industry, Single Buyer, Pool Market, Hybrid Model

\begin{abstract}
Restructuring of electricity supply industry had begun in early $20^{\text {th }}$ centuries. Malaysia Electricity Supply Industry (MESI) has aimed to change its structure to a wholesale market model in 2005. Started in 1992, Independent Power Producers (IPPs) were introduced and since then MESI had applied the Single Buyer Model until today. Even though, the Single Buyer Model had passed several process of evolution, it still a form of imperfect competition in which there is only one buyer and many sellers of a product. Therefore, other alternatives of electricity market model for MESI have been proposed, in order to carry on the MESI previous plan towards restructuring. This paper discusses three electricity market models; Single Buyer Market Model, Pool Market Model and Hybrid Market Model. The case study is carried out to compare the three market models in term of generation revenue. Data from 14 IPP and load profiles in MESI is used for the case study and the result will be discussed.
\end{abstract}

Introduction - The historical evolution of the Malaysian Electricity Supply Industry (MESI) leading to the formalization of the single buyer. Worldwide experience with the single buyer model has raised concern on how this model may backfire. Lack of transparency and fairness, poor system planning and non-competitive procurement are some of the drawbacks of a poorly constructed single buyer. Several observers citing conflict of interest, duplication of cost and tariff hikes. However, within Incentive-based regulation, single buyer is incentivized to be more efficient and transparent. These concerns can be mitigated as long as the single buyer remains regulated. MESI continues to face multi-dimensional challenges in term of tightness in fuel supply, industry governance and unsustainable tariff structure. The MESI reform transformation is clearly underway and more reform initiatives is expected to be implemented in the near future.

Pool Market Model - The pool market model is one of the most preferred electricity market model implemented in many developing countries [1]. Focus on the pricing issue in pool market by extending the capacity payment mechanism in the single electricity market. The clustering capacity price approach in the capacity payment mechanism is to provide more significant generation revenue for generator. Below are the discrepancies for the pure pool market, single electricity market and pool clustering capacity price.

Pure Pool Market - Pay the generator via the tool purchase price based on the SMP regardless the energy bid price [4].

$$
C_{P P}=S M P(1-L O L P)+V O L L(L O L P)
$$

LOLP signifies the loss of load probability and VOLL is value of loss load. The revenue for a power producer $i$ can be mathematically expressed as

$$
C_{P M i}=P_{P G i} \times C_{P P}
$$


which $P_{G i}$ signifies power capacity available by $i$ th generator to the pool in $\mathrm{MW}, C_{P P}$ is pool purchase price in RM/MWh, $k$ is numbers of generators involved and $G_{T}$ is total generator income in $\mathrm{RM} / \mathrm{h}$. Total revenue for all power producers can be written as

$$
G_{T}=\sum_{i=1}^{k}\left(P_{G i} \times C_{P P}\right)
$$

All in-merit generators will be paid based on uniform price.

Single Electricity Market (SEM) - SEM pay the generator via the $C p p$ based on the SMP regardless the energy bid price. The mathematical equations can be expressed as below which $P_{G i}$ signifies the output power from the generator $i$ and $C p p$ is the power purchase price. The capacity payment is calculated from the operating cost of the best new entrant (BNE) power plant [1]. Principally, the operating cost is depending on the type of generator, the location and fuel used to generate electricity. The lowest operating cost among the generators will be chosen as the capacity price [1].

$$
G_{i}=P_{G i} \times C_{p p}
$$

Pool Clustering Capacity Price - Pool Clustering introduces the capacity payment mechanism with clustering system for pool market. The pool clustering method placed generators into different cluster depend on generator types [1]. Each cluster has own capacity price. Capacity payment is paid off even though some of generator not generating during low demand.

Single Buyer Model - There are two payment types in single buyer which are energy payment and capacity payment [2]. The energy payment in the PPA is a "pay as you use" payment meaning that the TNB will only pay for the amount of the energy it took from the IPP. The energy price is the key of the pattern dispatch. Ideally, only the cheaper generator or lowest running cost generator should be generating power to meet load demand. Therefore the mathematical equation which represents this type of payment for each IPP can be written as:

$$
G_{E i}=P_{E G i} \times C_{E g i}
$$

which $G_{E i}$ signifies energy payment for each generator, $P_{E G i}$ is power output and $C_{E g i}$ is energy price.

The capacity payment is the amount of payment which TNB has to pay regardless whether the generated power is used or not [5]. The capacity payment is a mean for the IPP to recover a portion of its investment. The role for this payment is to provide extra revenue to the generator which are not generated thorough the charge of energy price. Therefore the mathematical equation which represents this type of payment for each IPP can be written as:

$$
G_{i}=P_{G i} \times C_{G i}
$$

which $G_{i}$ signifies capacity payment for each generator, $P_{G i}$ is available capacity and $C_{G i}$ is capacity price. Therefore, the mathematical equation for total revenue for power producers will be

$$
G_{T}=\sum_{i=1}^{k}\left[\left(P_{G i} \times C_{G i}\right)+\left(P_{E G i} \times C_{E g i}\right)\right]
$$

Hybrid Market Model - A hybrid market model is to satisfy the generator revenue adequacy in Malaysian electricity market under a competitive environment [4]. In the hybrid market model, the load demand is divided into two parts; base load demand and peak load demand [3]. In the base load demand, the load is distributed to the generators based on the pro-rata basis. There is no competition among generators and the generators will share this load proportional to their available capacity, i.e. generators with higher available capacity will have high percentage share of the base 
load demand. The remaining high load demand will be traded through competition of the energy bid price offered by each generator. Generator with a lower energy bid price has the priority to supply the remaining demand. The generator's payment for the base load demand would be based on the SMP while for the remaining load demand would be based their energy bid price. The MW level of base load demand will be determined from the daily load curve. The mathematical equation that represents each generator's contribution to the base load demand can be written as;

$$
P_{G i b l}=\frac{P_{G i}}{\sum_{i-l}^{k} P_{G i}} \times P_{G T b l}
$$

which $P_{\text {Gibl }}$ signifies generator share of base load demand, $P_{G i}$ signifies available capacity of a generator $G_{i}$ and $P_{G T b}$ is identified base load demand.

\section{Result and Discussion}

Figure 1 shows the total generation revenue in a day of 14 generators for weekday load profile. All 14 generators are able to supply electricity regardless their bid prices. For pure pool market system, Gen 14 received zero revenue. For SEM, all 14 generators have obtained the generation revenue due to chances of supplying electric power. Pool clustering capacity price and SEM assure a worth generation revenue for all generators. The pool clustering capacity price guarantees the welfare for all generators regardless the variation in electricity demand. The clustering system offers reasonable capacity payment for all types of generators. Although, expensive generators are incapable to compete during low load demand but with the capacity payment received might reduce the financial burden.

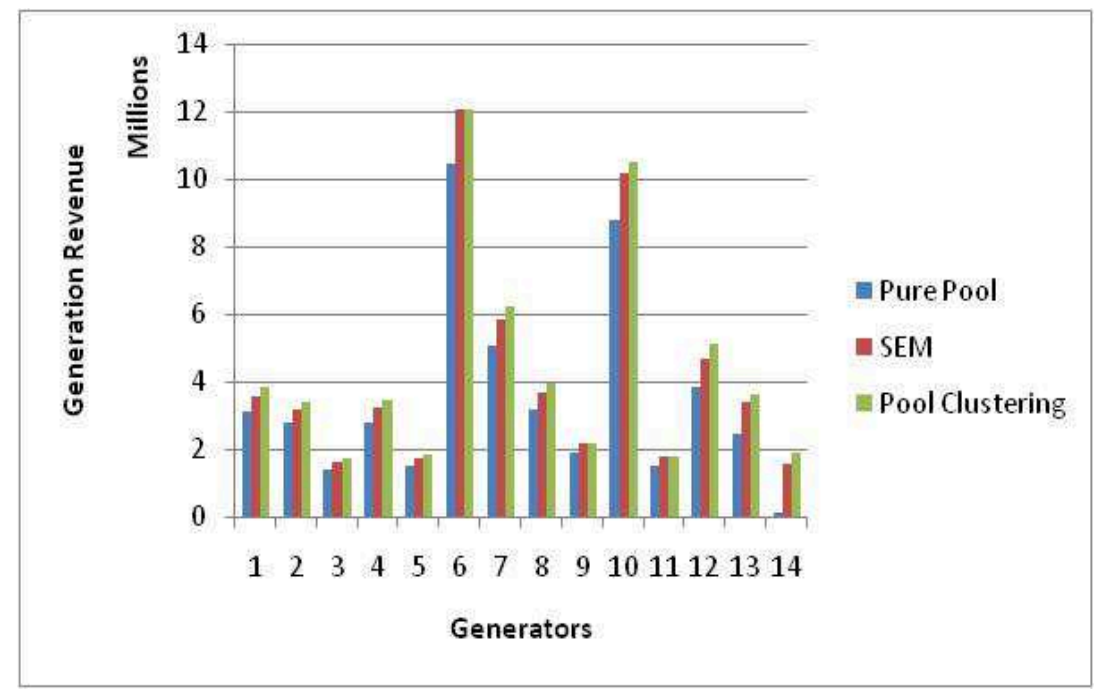

Figure 1 : The total generators' revenue in a day for weekday load profile

Figure 2 shows that the total hourly revenue of 14 IPPs resulted from single buyer, pure pool and hybrid market model for weekday respectively. On a weekday, it can be seen that at low load demand, the generator revenue for both pool and hybrid market model are quite similar. At low load condition, the generators would gain more revenue under single buyer compare to other market as the generators still receive a fixed capacity payment. However, when the load demand is high, the generator revenues under pure pool market are much higher than the hybrid method. This is due to the increasing value of SMP, which produced higher pool purchasing price Cpp to be paid to the IPPs. When the hybrid market model is applied, the Cpp value is reduced because base demand is considered for every hour. It is shown that the hybrid market model has merit over the pure pool market in providing fair generator revenue over trading hours. During low demand, the pure pool 
market cannot guarantee hourly generator revenue for expensive generators. Some of IPPs might lose their revenue because of non-participation in the trading. With the hybrid market model, all IPPs have equal opportunities to participate in the trading and receive some revenue from their contribution in base load demand. Therefore, the efficiency of the power producer is always kept at the adequate level.

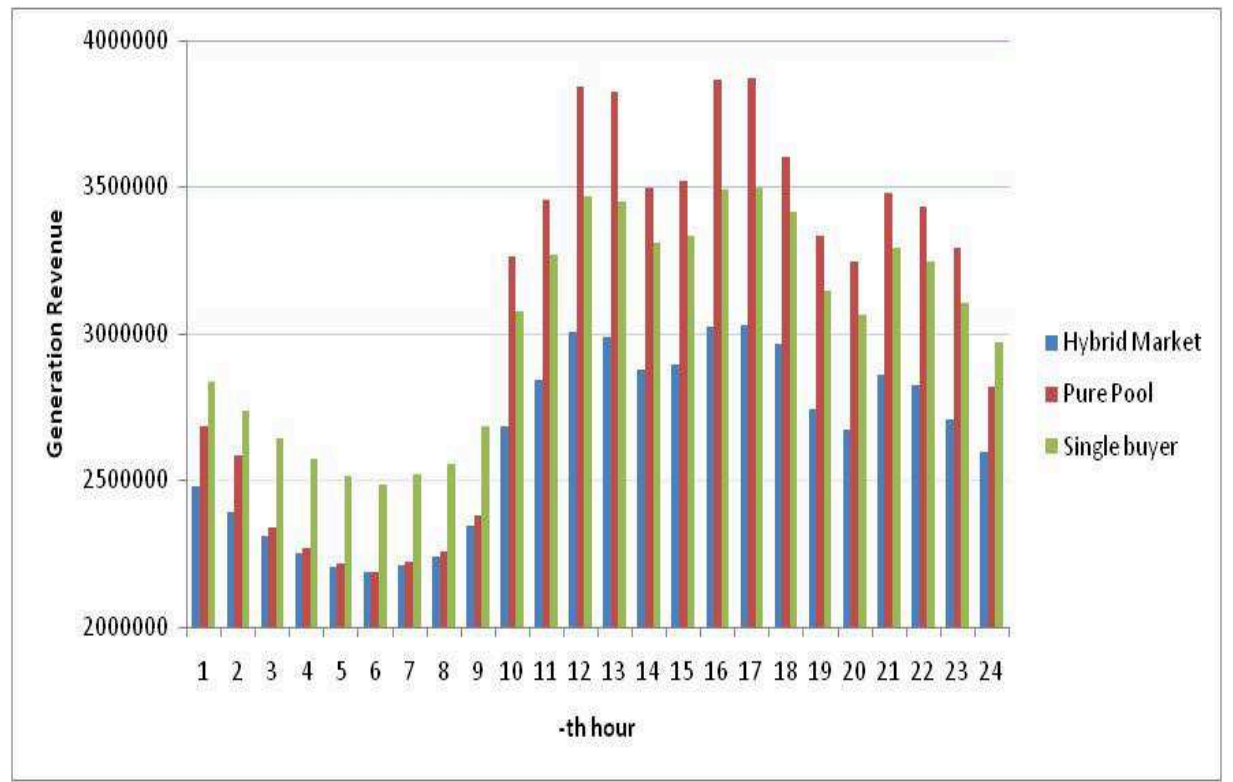

Figure 2 : Total generation revenue at each hour for weekday load profile

\section{Conclusion}

The pool clustering introduces the capacity payment mechanism. Even though all generators could recover their operation and maintenance costs by bidding higher during peak load demand, having the capacity payment could smooth out energy price and help maintain the reserve margin. The pool clustering with clustering capacity price ensures the welfare of all generators in electricity supply industries. It is shown that the pool clustering provides adequate generation revenue to all generators compared to both pure pool and single electricity market. For that reason, all 14 generators and consumer are able to experience a more competitive environment with efficient electricity supply. Meanwhile, the hybrid market model can overcomes the weaknesses of the existing single buyer due to capacity payment and the pool market for guaranteed revenue remuneration of the generator. The base load demand sharing approach ensures the involvement of all IPPs in the hourly trading period. The hybrid market model is believed able to offer a fair competitive environment among power producers. Finally, if either the pool clustering capacity payment or the hybrid market model can be executed by MESI, the generators will get reasonable profit, the distributor company will be able to pay appropriate amount and end-consumers will enjoy a low electricity tariff.

\section{References}

[1] N. Othman, M.Y. Hassan and F. Hussin, Generation Revenue Assessment in Pool-Based Electricity Markets, IEEE, 978-1-4673-5019-8/12, 2012.

[2] Noor Zafina Mohd Zamin, Nor Ziha Zainol Abidin and Joon B. Ibrahim, Single Buyer- A Step Forward in Malaysian Electricity Supply Industry Reform, IEEE, 978-1-4673-6349-5/13, 2013.

[3] Hassan, Mohammad Yusri and Hussin, Faridah and Othman, Mohd. Fauzi, A Study of Electricity Market Models in The Restructured Electricity Supply Industry. Project Report. Faculty of Electrical Engineering, Universiti Teknologi Malaysia Skudai, Johor, VOT 78178, 2009. 
[4] Nurehan Othman, Mohammad Yusri Hassan, Faridah Hussin, Md Pauzi Abdullah, Generator Revenue Adequacy in the Competitive Electricity Markets : The case of Malaysia, International Journal of Integrated Engineering, Vol. 5 No. 3, p. 26-35, 2013.

[5] Aifa Syireen Binti Arifin, Pool Based Electricity Market Design For Malaysia Electricity Supply Industry. Thesis Report. Faculty of Electrical Engineering, Universiti Teknologi Malaysia, 2008.

[6] Zaris Izzati Mohd Yassin, Exploring The Bilateral And Hybrid Model In Deregulated Electricity Market. Thesis Report. Faculty of Electrical and Electronic Engineering, Universiti Tun Hussein Onn Malaysia, 2014.

[7] Amir Khalid, "Effect of ambient temperature and oxygen concentration on ignition and combustion process of diesel spray", Asian Journal of Scientific Research, Volume 6, Issue 3, 2013, Pages 434-444, DOI: 10.3923/ajsr.2013.434-444.

[8] Amir Khalid, Keisuke Hayashi, Yoshiyuki Kidoguchi , Tomoaki Yatsufusa, "Effect of air entrainment and oxygen concentration on endothermic and heat recovery process of diesel ignition", (2011) SAE Technical Papers, DOI: 10.4271/2011-01-1834.

[9] Archana Singh and Prof. D.S. Chauhan, Electricity Sector Restructuring Experience of Different Countries, IJSER, ISSN 2229-5518, 2011.

[10] An Introduction to Australia's National Electricity Market, ISBN 0-646-41233-7, 2010. 